Equivalent Slot Thermal Conductivity and Back-iron Extension Effects on Machine Cooling Zhang, F., Gerada, D., Xu, Z., Zhang, H., Gerada, C.

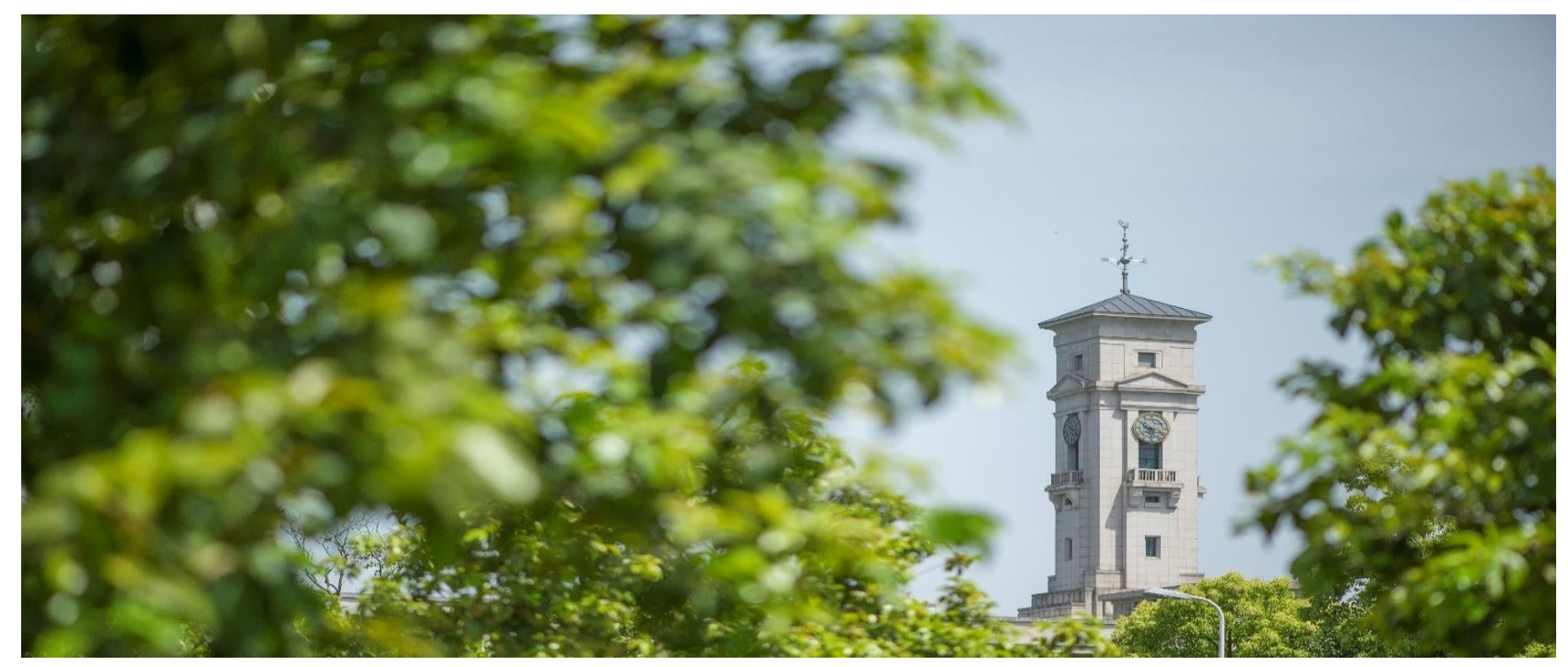


University of Nottingham Ningbo China, 199 Taikang East Road, Ningbo, 315100, Zhejiang, China.

First published 2019

This work is made available under the terms of the Creative Commons Attribution 4.0 International License:

http://creativecommons.org/licenses/by/4.0

The work is licenced to the University of Nottingham Ningbo China under the Global University Publication Licence:

https://www.nottingham.edu.cn/en/library/documents/researchsupport/global-university-publications-licence.pdf 


\section{Equivalent Slot Thermal Conductivity and Back-iron Extension Effects on Machine Cooling}

\author{
Fengyu Zhang \\ Key Laboratory of More Electric \\ Aircraft Technology of Zhejiang \\ Province \\ University of Nottingham Ningbo \\ China \\ Ningbo, China \\ fengyu.zhang@nottingham.edu.cn
}

PEMC, University of Nottingham

Nottingham, United Kindom

Key Laboratory of More Electric

Aircraft Technology of Zhejiang

Province

University of Nottingham Ningbo China

Ningbo, China

he.zhang@nottingham.edu.cn
David Gerada

PEMC, University of Nottingham

Nottingham, United Kindom

Key Laboratory of More Electric

Aircraft Technology of Zhejiang

Province

University of Nottingham Ningbo

China

Ningbo, China

david.gerada@nottingham.ac.uk

Chris Gerada

PEMC, University of Nottingham

Nottingham, United Kindom

Key Laboratory of More Electric

Aircraft Technology of Zhejiang

Province

University of Nottingham Ningbo

China

Ningbo, China

chris.gerada@nottingham.ac.uk

\author{
Zeyuan $\mathrm{Xu}$ \\ PEMC, University of Nottingham \\ Nottingham, United Kindom \\ Key Laboratory of More Electric \\ Aircraft Technology of Zhejiang \\ Province \\ University of Nottingham Ningbo \\ China \\ Ningbo, China \\ zeyuan.xu@nottingham.ac.uk
}

\begin{abstract}
Back-iron Extension (BIE) is an effective thermal management technique which reduces the winding temperatures by projecting part of the back iron into the center of slot, thereby shortening the heat transfer path between the coil and back iron. Based on an existing concentrated-wound traction motor, this paper investigates the effects of equivalent slot thermal conductivity of coil on the optimal back iron extension geometry and temperature reduction.
\end{abstract}

Keywords-equivalent thermal conductivity, thermal management, slot cooling, back-iron extension

\section{INTRODUCTION}

Thermal management is a key enabler for pushing technical boundaries of higher power density $(\mathrm{kW} / \mathrm{kg})$, and lower cost $(\$ / \mathrm{kW})$, which are important figures of merit in transport electrification, being it for aerospace, rail, or automotive $[1,2]$. Temperature reduction with advanced cooling brings the consequent reduction in active materials, such as copper and iron [3].

Compared to air forced cooling [4], liquid cooling provides a more efficient cooling system. For a conventional water jacket cooling system [5-11], where the stator core is enclosed by the housing that carries water, the heat generated in the slot are dissipated to the water jacket, via slot, slot liner, back-iron and housing. The cooling system can be enhanced by slot cooling [12, 13], or oil spray cooling for the endwinding region, which is investigated in [14-16], shortening the heat transfer path between the coolant and the slot. Reference [17] compares three identical prototypes with the aforementioned different cooling schemes: prototype A with micro-channel cooling jacket surrounding the stator lamination, prototype $\mathrm{B}$ with endwinding spray added to the micro-channel cooling jacket, and $\mathrm{C}$ prototype with slot cooling tubes added to the micro-channel cooling. The relative trade-off between the three cooling schemes is

This work was supported by the Ningbo Science \& Technology Beauro under Grant 2018B10002. This work was supported by the China NSFC under Grant 51607099 and by the Ningbo Science \& Technology Beauro under Grant 2017D10029. compared and presented. Both prototype $\mathrm{B}$ and prototype $\mathrm{C}$ show a better thermal performance than the prototype A: Prototype $\mathrm{B}$ and $\mathrm{C}$ can be run the whole speed range for the same thermal limit, while water jacket only with prototype A is not sufficient. Prototype $\mathrm{C}$ shows a maximum cooling effectiveness with a fairly simply system compared to prototype B. However, both the slot cooling and oil spray cooling needs delicate design to achieve a good cooling thermal performance, which complicates the cooling system. Moreover, extra pump power is required, which may also need larger space. Meanwhile, for oil spray cooling, nozzle erosions should also be taken into consideration. For the aforementioned consideration, water jacket cooling is still widely be used for the high power density machines.

Compared to the aforementioned novel cooling topologies, new materials brings large temperature reduction without causing extra problems to the existing cooling systems. For water jacket cooling, [18] summarizes that equivalent slot thermal conductivity is very important on the thermal condition of the electrical machines, which is strongly influenced by the impregnation resin material. Slot impregnation material, varnish, Epoxylite and a siliconebased thermally conductive materials SbTCM are studied in [18] on identical induction machines. It is shown that using impregnation material with higher thermal conductivities leads to significant temperature reduction in electrical machines and thus higher current loading capability. It is determined that $10 \%-15 \%$ and $25 \%-30 \%$ increases in current loading capability of the studied machines are achievable with the varnish replaced by epoxylite and SBTCM, respectively. The new material can also be applied to different occasions, such as encapsulating, potting or impregnating the conductor bundle [19]. However, the new material development often come with an increased cost premium. The impregnation thermal conductivity is in direct linear relationship with the cost: the higher the thermal conductivity of the impregnation resin is, the higher the cost. 
With a ' $T$ ' shape high thermal conductivity material inserted in the middle of the windings, a $40 \%$ temperature reduction is achieved for a low frequency electrical machine. The ' $T$ ' base provides a large contact area between the winding and the stator and therefore shortens the heat transfer path between the slot and coolant with high thermal conductivity [20]. The thermal benefits with the ' $T$ ' shape insertion are largely linked with the contact effectiveness between the copper and the slot. Moreover, it should be noted that eddy current losses generated within the material, which may mitigate the thermal benefits it brings.

Heat pipes made of graphite sheets, whose thicknesses is around $100 \mu \mathrm{m}$ and thermal conductivities around 700 $\mathrm{W} /(\mathrm{mK})$, are supposed to have good cooling performance if they are placed in the winding pack thermally connecting the slot to the water jacket in the housing, shortening the heat transfer path [21]. Compared to the high thermal conductivity materials in [20], there are low eddy currents losses generated inside the graphite sheets. However, due to challenges in manufacturing, the graphite sheets are only located in the inner and outer surfaces of the windings with the conducted experiment and does not show any thermal benefits compared to the traditional water jacket cooling.

A simple, novel, low cost and effective way is proposed in [22] to improve the motor thermal performance by extending a part of back-iron along the centerline into the slot. A significant $26.7 \%$ temperature reduction is achieved with the experimental validation. It is pointed that the thermal benefits with the back-iron extension (BIE) are more significant for single-layer concentrated windings where the coil section is usually thicker. As a follow-on study, this paper contributes one more parameter that affects the effectiveness of the back-iron extension, the equivalent slot thermal conductivity (ESTC). This paper is organized as follows, the thermal model with which the research is based on is described in section II. The methodology to investigate the relationship between the SETC and BIE thermal benefits is detailed in section III. Experimental validation is conducted in section IV. Finally, section V concludes the paper.

\section{THERMAL MODEL}

For electrical machines equipped with a water jacket cooling arrangement, most heat generated inside the slot is dissipated to the stator tooth and then to back-iron, or directly to back-iron, and then to the coolant. On the heat transfer path, slot radial resistance is a complex value, which is determined by the properties of the constituent materials inside the slot, including the copper, enamel, impregnation resin, and slot liner between coil and stator lamination. Also due to large amount of heat is generated in the coil, slot radial thermal resistance is critical in determining the heat dissipation efficiency to water jacket. A back-iron extension (BIE) in Fig. 1, the thermal conductivity of which is much higher than ESTC of the coil, shortens the heat transfer path between the back-iron and the hot spot in the slot located at the slot center. The thermal performance of the electrical machines, therefore, could be improved with the using of BIE inside the slot.

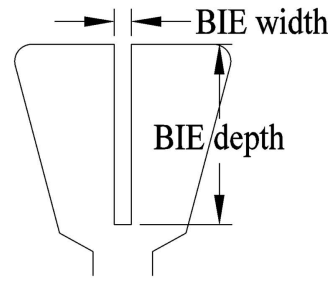

Fig. 1. Back-iron extension

ESTC is variable for different electrical machines, the effects of which on the BIE thermal benefits are investigated in this research. Two existing stator segment based on a traction machine with applied BIE geometry and without are used as a case study [22], the correlation between ESTC and $\mathrm{BIE}$ thermal benefits is derived. Firstly, this section details the thermal model used for the ESTC effects analysis, followed by the thermal results and discussion.

\section{A. Segment designed for the thermal model validation}

The existing 75-kW, 12-slot, 8-pole permanent magnet machine with concentrated winding, applied to an electric vehicle (EV) is shown in Fig. 2(a) with relevant detailed data listed in [22]. Temperature sensors installed in the traction machine are able to give accurate peak winding temperature, while the temperature distribution can not be captured due to the limited numbers of thermocouples.

Therefore, one stator segment with a water jacket cooling specially designed for the thermal testing with enough thermocouples installed at sensitive locations is shown in Fig. 2(b). Iron losses are neglected as they are small compared to copper losses, therefore, the stator is made of solid steel for the sake of manufacturing simplicity. Meanwhile, the segment is thermally insulated to make sure all the heat is dissipated to the water jacket.

\section{B. 3D thermal model comparison between the whole motor and the segment}

A 3D thermal model developed for the segment is modified from the traction motor thermal model, shown in Fig. 3 (a). Exploiting the machine symmetry, half slot and the corresponding rotor and endwinding are simulated in the thermal model for the whole motor. Fig. 3 (a) shows that there are 30 nodes, including both radial and axial directions. It is worth noting that the half slot is represented by one node for the sake of simplicity in Fig. 3, while there are $5 * 5$ nodes evenly distributed in half the slot. All the nodes in Fig. 3 are linked with conduction thermal resistance or convection thermal resistance calculated with formulas in [22]. Losses marked with [॰] in Fig. 3 (a) are evenly distributed.

The LPTN thermal model developed for the full machine in Fig. 3 (a) is adjusted to simulate the segment in Fig. 2(b) with practical changes, mainly removing the rotor. The thermal condition that there is no convection heat transfer in the airgap or in the endwinding region is assumed, as the stator segment is thermally insulated by a thick insulation layer. Therefore, all the heat generated are removed by the water flowing in the coolant channel. Also, since DC current is applied to the stator, only copper DC losses are considered for the segment, while there are no stator iron losses generated. Therefore, for the thermal model developed for the segment, there are 14 nodes in the modified 3D thermal model, shown in Fig. 3 (b). 


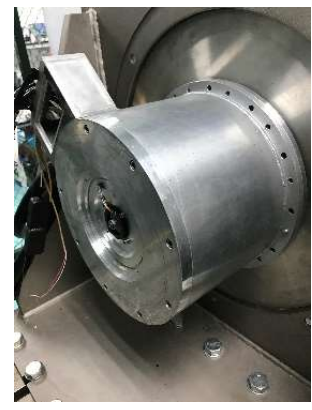

(a)

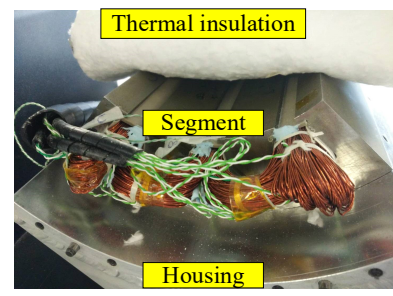

(b)

Fig. 2. (a) Traction machine (b) Segment

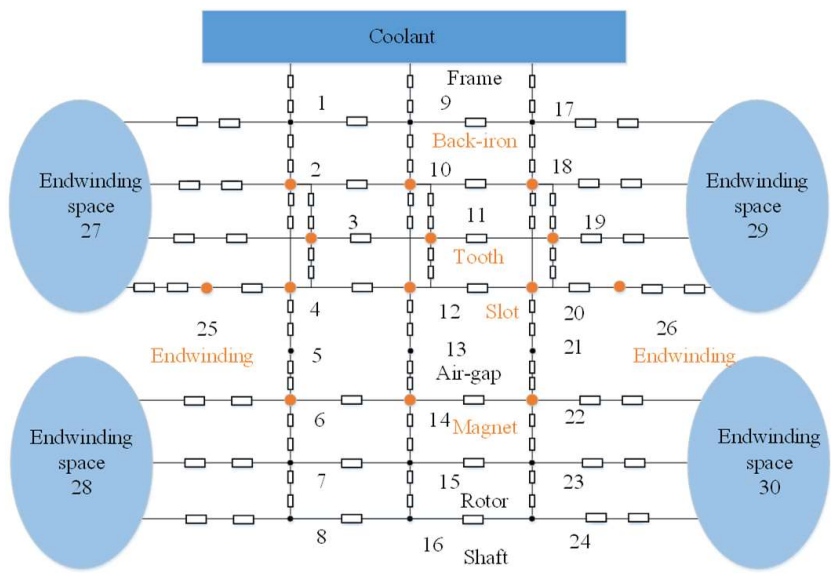

(a)

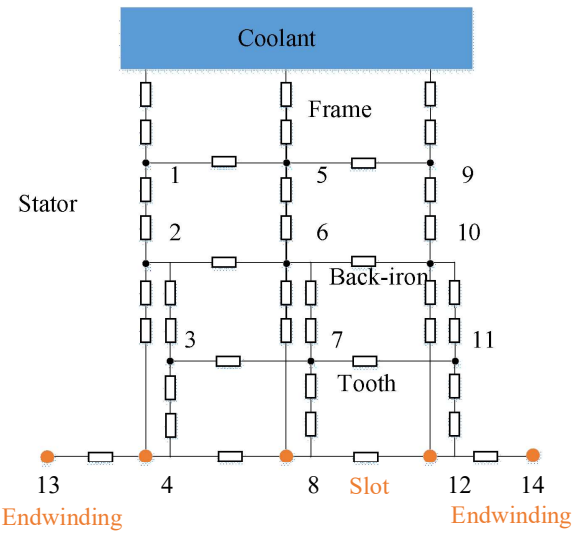

(b)

Fig. 3. 3D thermal model (a) whole motor (b) segment

\section{Analysis for the ESTC effects on BIE thermal benefits}

For a water jacket cooled machine, the hot spot is usually located in the middle of the slot due to high heat loss and lower thermal conductivity of coil. BIE, whose radial thermal conductivity $(\sim 20 \mathrm{~W} / \mathrm{mK})$ is much higher than coil $(0-2$ $\mathrm{W} / \mathrm{mK}$ ), forming a heat short cut of the heat transfer from coil center to the back-iron and then to the water jacket. The thermal conductivities difference between BIE material and ESTC of coil affect the BIE thermal performances. Meanwhile, the losses generated inside the slot, are also considered as one parameter that affect thermal benefits of applying BIE.

In this paper, a $2.2 \mathrm{~mm}$ wide BIE and having a depth equal to slot depth is proposed, accounting for multiple factors, including flux leakage and reduced slot fill factor, as with the electrical machine studied in [22]. Experimental tests conducted between the original segment and segment with BIE shows that $26.7 \%$ temperature reduction is achieved. In this research, a similar BIE geometry is applied.

The tendency of absolute peak winding temperature versus ESTC for both segments with BIE and without are plotted in Fig. 4. Taking into account the thermal conductivity of various commercially available resins, the ESTC ranges from 0.1 to 5 $\mathrm{W} / \mathrm{mK}$. Meanwhile, the tendency is also recorded for three different current densities: $6.13,7.3$ and $8.75 \mathrm{~A} / \mathrm{mm}^{2}$.

It can easily be seen from Fig. 4 that for each curve(with and without BIE), the peak winding temperature at the endwinding reduces sharply with ESTC at the first stage, while it almost flats out when ESTC continues increasing. When the ESTC is small, it is one of the main factors that affects the thermal performances of the electrical machines, and for such low values it is where the BIE is most effective. However, further increase in ESTC does not necessarily introduce thermal improvements and also reduces the impact of BIE.

It is expected that the peak winding temperature is in positive correlation with current density. For each current density, thermal improvement is inspected in the segment with $\mathrm{BIE}$, compared to the segment without. For example, there is temperature drop between the lines marked with [ $\mathbf{\square}]$ and [ $\square]$ for $8.75 \mathrm{~A} / \mathrm{mm}^{2}$ current density, representing segment with $\mathrm{BIE}$ and without, respectively.

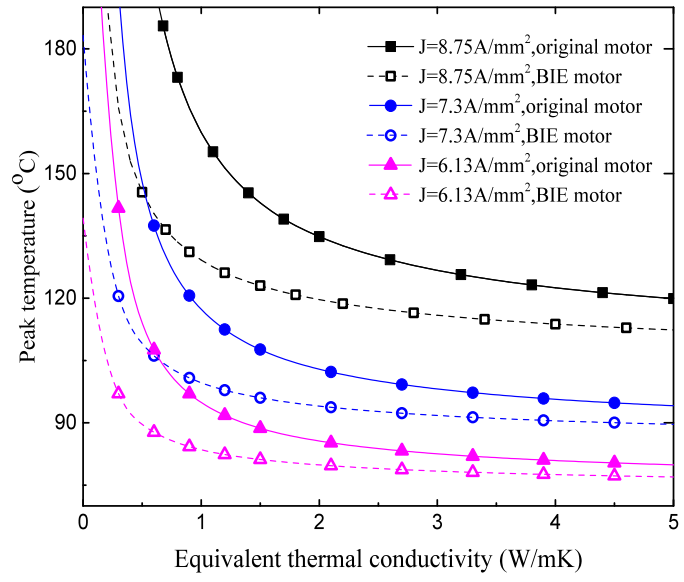

Fig. 4. Original segment and BIE segment peak temperature comparison with ESTC 


\section{Equivalent slot thermal conductivity and back-iron extension effectivenss}

To clearly present the relationship between ESTC and BIE thermal benefits, Fig. 5 is derived from Fig. 4. In Fig. 5, the temperature difference between the segment with BIE and without is plotted versus ESTC, with each line in - , - representing current densities $8.75 \mathrm{~A} / \mathrm{mm}^{2}, 7.3 \mathrm{~A} / \mathrm{mm}^{2}$ and $6.13 \mathrm{~A} / \mathrm{mm}^{2}$, respectively. The larger the difference between the BIE thermal conductivity and ESTC, the larger the temperature reduction (thermal benefits) can be seen from Fig. 5 .

Fig. 4 concludes that the effect of ESTC on peak winding temperature is not significant when it reaches certain value. For example, for original segment with current density 6.13 $\mathrm{A} / \mathrm{mm}^{2}$, temperature remains almost constant when the ESTC is larger than $1.4 \mathrm{~W} / \mathrm{mK}$. For original segment with current density $8.75 \mathrm{~A} / \mathrm{mm}^{2}$, ESTC effects are not significant when it is larger than $2.5 \mathrm{~W} / \mathrm{mK}$. Though the turning point of the ESTC value is different, each line in Fig. 4 will gradually flatten out with ESTC. Therefore, both the peak winding temperature for segment with BIE and without will become parallel lines for high ESTC. Fig. 5 varifies that no significant temperature reduction is observed with BIE when ESTC continues increasing. It also indicates that higher current density results in larger thermal benefits for the same geometrical design of BIE.

\section{EXPERIMENTAL VALIDATION}

\section{A. Segment}

Fig. 6 shows a 3D printed example of a stator segment with BIE, which is used to determine the copper filling factor inside the slot. The wedge size is specially designed for the segment testing, while its effects on the electromagnetic aspects are ignored.

Similar stator segment to Fig. 2 (b) with BIE is manufactured with iron, shown in Fig. 7. Thermocouples are placed on the back-iron to ensure a good contact between the stator and the housing. The segments with BIE and without are tested in two conditions, un-varnished in the first instance, and then with varnished ones. On completion of the tests with the unvarnished segments in Fig. 7 (a), the two segments are sent for varnishing by vacuum pressure impregnation (VPI) which ensures a good fill by the impregnation, shown in Fig. 7 (b) and (c).

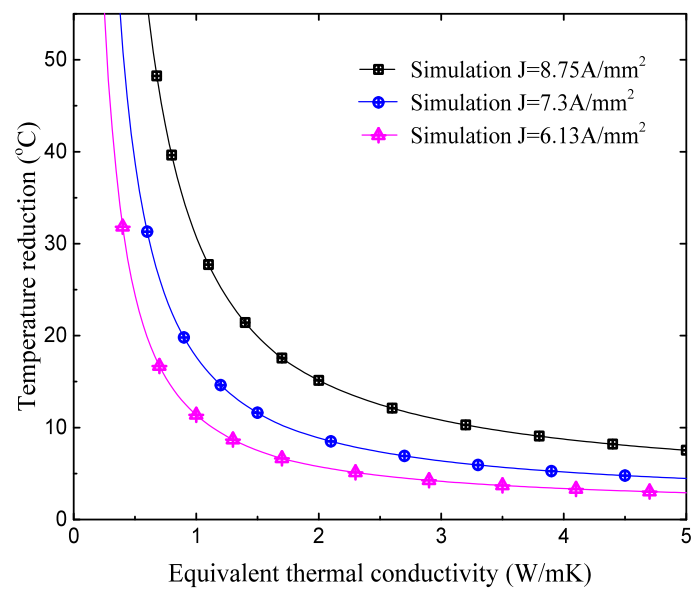

Fig. 5. Back-iron extension thermal benefits for different equivalent slot thermal conductivities

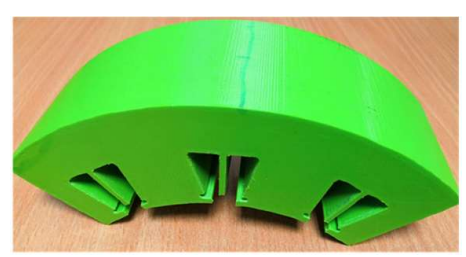

Fig. 6. Back-iron extension mock stator for copper fill factor determination

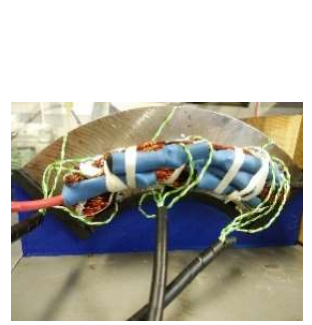

(a)

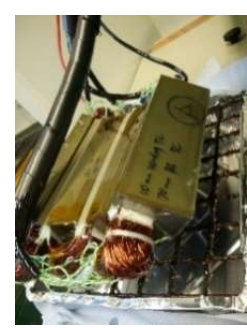

(b)

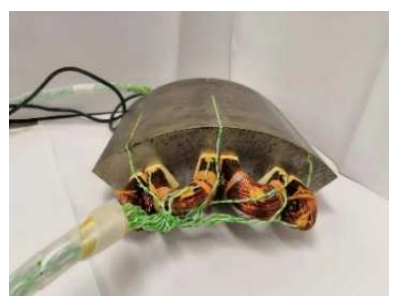

(c)

Fig. 7. Back-iron extension stator segment (a) without varnish; (b) in varnished process; (c) with varnish

\section{B. Experimental test rig}

The experimental test rig is detailed in Fig. 8, including the segment under test, DC power supply, temperature logger and water chiller. Winding temperature is measured with $\mathrm{K}$ thermocouples, ranging from $-75^{\circ} \mathrm{C}$ to $250^{\circ} \mathrm{C}$.

\section{Experimental results}

Fig. 4 shows that for the same thermal limit, the maximum current density applied to the segments is different with different ESTC. The thermal limit of the wire used in the segments is $180^{\circ} \mathrm{C}$. For the varnished original segment, the current density reaches to $8.75 \mathrm{~A} / \mathrm{mm}^{2}$, while it is $7.3 \mathrm{~A} / \mathrm{mm}^{2}$ for the un-varnished original segment, owning to the lower thermal conductivity of air with respect to that of the resin.

Fig. 9 shows experimental results to verify some of the analysis presented in this paper. The temperature reduction for the experiment is marked with dots in $[\diamond]$ and $[4]$ for the segments with varnish $($ ESTC $\approx 0.7)$ and without varnish (ESTC $\approx 0.3$ ), respectively, which agrees well with the predicted temperature.

The temperature reduction with $\mathrm{BIE}$ for segments with varnish and without is $20^{\circ} \mathrm{C}$ and $34^{\circ} \mathrm{C}(70 \%)$, respectively, when the current density is $6.13 \mathrm{~A} / \mathrm{mm}^{2}$. It shows that with lower ESTC, the thermal benefits with BIE is larger. Same phenomenon has been observed with current density 7.3 $\mathrm{A} / \mathrm{mm}^{2}$, with which temperature reduction is $30^{\circ} \mathrm{C}$ and $54^{\circ} \mathrm{C}(80 \%)$ for segments with varnish and without, respectively. 


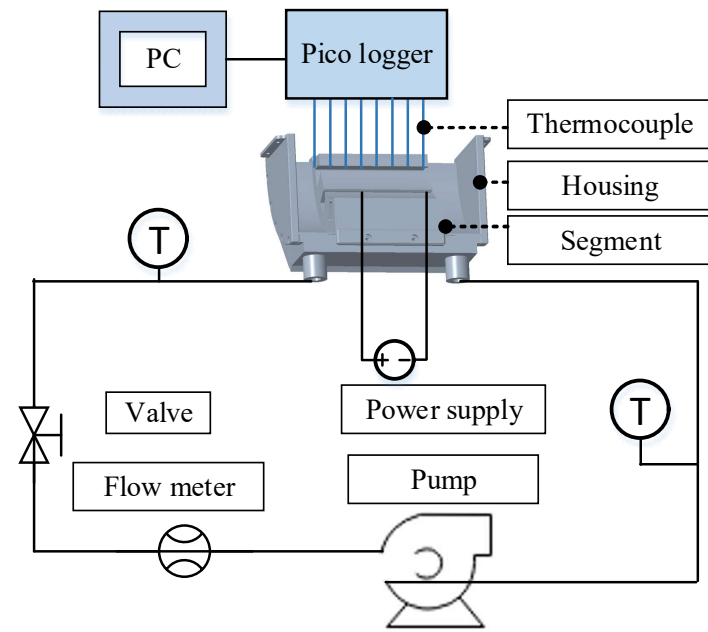

Fig. 8. Experimental rig

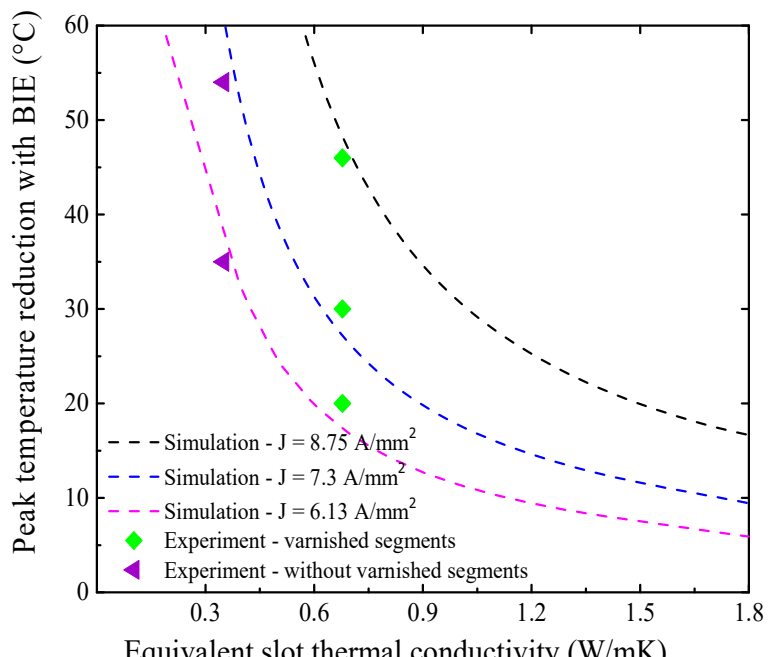

Equivalent slot thermal conductivity $(\mathrm{W} / \mathrm{mK})$

Fig. 9. Experimental results

\section{CONCLUSION}

Thermal improvement is one key enabler for next generation high power density electrical machines, leading to various developed novel cooling techniques. Back-iron extension is reported recently with significant thermal benefits. This paper investigates in detail the relationship between the effectiveness of back-iron extension and different slot material compositions, which translate to different equivalent slot thermal conductivities. It is summarized that for electrical machines with poor equivalent slot thermal conductivity, more significant temperature reduction with back-iron extension is expected.

\section{REFERENCES}

[1] D. Gerada, A. Mebarki, N. L. Brown, C. Gerada, A. Cavagnino, and A. Boglietti, "High-speed electrical machines: Technologies, trends, and developments," IEEE Transactions on Industrial Electronics, vol. 61, no. 6, pp. 2946-2959, 2014.

[2] D. Golovanov, L. Papini, D. Gerada, Z. Xu, and C. Gerada, "Multidomain Optimization of High-Power-Density PM Electrical Machines for System Architecture Selection," IEEE Transactions on Industrial Electronics, vol. 65, no. 7, pp. 5302-5312, 2018.
[3] G. Sugden, "Oil-cooled ac generators for aircraft—present trends," Students' Quarterly Journal, vol. 40, no. 160, pp. 128-133, 1970.

[4] L. Kung, U. Bikle, O. Popp, and R. Jakoby, "Improvement of the cooling performance of symmetrically self-ventilated induction machines in the 2-15 MW range," in IEMDC 2001. IEEE International Electric Machines and Drives Conference (Cat. No.01EX485), 2001, pp. 673-680.

[5] W. Jiang and T. M. Jahns, "Coupled Electromagnetic-Thermal Analysis of Electric Machines Including Transient Operation Based on Finite-Element Techniques," IEEE Transactions on Industry Applications, vol. 51, no. 2, pp. 1880-1889, 2015.

[6] J. Zhang, Z. Zhang, and L. Yu, "Thermal Deformation Analysis of Water Cooling Doubly Salient Brushless DC Generator with Stator Field Winding," IEEE Transactions on Industrial Electronics, pp. 1-1, 2019.

[7] J. Li, Y. Lu, Y. Cho, and R. Qu, "Design, Analysis and Prototyping of a Water-Cooled Axial Flux Permanent Magnet Machine for Large Power Direct-Driven Applications," IEEE Transactions on Industry Applications, pp. 1-1, 2019

[8] X. Fan, D. Li, R. Qu, and C. Wang, "A Dynamic Multilayer Winding Thermal Model for Electrical Machines With Concentrated Windings," IEEE Transactions on Industrial Electronics, vol. 66, no. 8, pp. 61896199, 2019.

[9] R. J. Wang and G. C. Heyns, "Thermal analysis of a water-cooled interior permanent magnet traction machine," in 2013 IEEE International Conference on Industrial Technology (ICIT), 2013, pp. 416-421.

[10] L. Ye, D. Li, Y. Ma, and B. Jiao, "Design and Performance of a Watercooled Permanent Magnet Retarder for Heavy Vehicles," IEEE Transactions on Energy Conversion, vol. 26, no. 3, pp. 953-958, 2011.

[11] C. Kral, A. Haumer, and T. Bauml, "Thermal Model and Behavior of a Totally-Enclosed-Water-Cooled Squirrel-Cage Induction Machine for Traction Applications," IEEE Transactions on Industrial Electronics, vol. 55, no. 10, pp. 3555-3565, 2008.

[12] S. A. Semidey and J. R. Mayor, "Experimentation of an Electric Machine Technology Demonstrator Incorporating Direct Winding Heat Exchangers," IEEE Trans. Industrial Electronics, vol. 61, no. 10, pp. 5771-5778, 2014.

[13] W. J. Chen Xiao, Griffo A., Spagnolo A., "Thermal Modelling of Hollow Conductors for Direct Cooling of Electrical Machines," IEEE Transactions on Industrial Electronics, 2019.

[14] T. Davin, J. Pellé, S. Harmand, and R. Yu, "Experimental study of oil cooling systems for electric motors," Applied Thermal Engineering, vol. 75 , pp. 1-13, 2015

[15] L. Zhenguo, L. Shaoyan, and R. Lin, "The effect of spray parameter on heat dissipation in spray evaporatvie cooling high power density motors," in Electrical Machines and Systems (ICEMS), 2017 20th International Conference on, 2017, pp. 1-4: IEEE.

[16] J.-y. Jia, Y.-x. Guo, W.-d. Wang, and S.-r. Zhou, "Modeling and experimental research on spray cooling," in 2008 Twenty-fourth Annual IEEE Semiconductor Thermal Measurement and Management Symposium, 2008, pp. 118-123: IEEE.

[17] A. M. E.-. Refaie et al., "Advanced High-Power-Density Interior Permanent Magnet Motor for Traction Applications," IEEE Transactions on Industry Applications, vol. 50, no. 5, pp. 3235-3248, 2014.

[18] S. Nategh, A. Krings, O. Wallmark, and M. Leksell, "Evaluation of impregnation materials for thermal management of liquid-cooled electric machines," IEEE Transactions on Industrial Electronics, vol. 61, no. 11, pp. 5956-5965, 2014.

[19] D. J. Powell, "Modelling of high power density electrical machines for aerospace," University of Sheffield, 2004.

[20] M. Galea, C. Gerada, T. Raminosoa, and P. Wheeler, "A thermal improvement technique for the phase windings of electrical machines," IEEE Transactions on Industry Applications, vol. 48, no. 1, pp. 79-87, 2012.

[21] A. Tüysüz, M. Steichen, C. Zwyssig, and J. W. Kolar, "Advanced cooling concepts for ultra-high-speed machines," in 2015 9th International Conference on Power Electronics and ECCE Asia (ICPEECCE Asia), 2015, pp. 2194-2202.

[22] F. Zhang et al., "Back-iron Extension Thermal Benefits for Electrical Machines with Concentrated Windings," IEEE Transactions on Industrial Electronics, pp. 1-1, 2019. 